\title{
All-Solid-State Ion-Selective Electrodes Based on Graphite Paste for Determination of Calcium(II) and Nitrate
}

\author{
Johannes Schwarz ${ }^{1}$, Ute Enseleit ${ }^{1}$, Kathrin Trommer ${ }^{1}$, Michael Mertig ${ }^{1,2}$ \\ ${ }^{1}$ Kurt-Schwabe-Institut für Mess- und Sensortechnik e.V. Meinsberg, 04736 Waldheim, Germany \\ ${ }^{2}$ Professur für Physikalische Chemie, Mess-und Sensortechnik, Technische Universität Dresden, 01062 Dresden, \\ Germany
}

Correspondence: Johannes Schwarz, Kurt-Schwabe-Institut für Mess- und Sensortechnik e.V. Meinsberg, Kurt-Schwabe-Strasse 4, 04736 Waldheim, Germany. E-mail: johannes.schwarz@ksi-meinsberg.de

Received: June 26, 2019 Accepted: July 25, 2019 Online Published: September 11, 2019

doi:10.5539/ijc.v11n2p156 URL: https://doi.org/10.5539/ijc.v11n2p156

\begin{abstract}
Robust and easy-to-handle ion-selective electrodes in all-solid-state configurations based on graphite paste have been developed for applications in environmental samples. The electrode consists of different functional layers (graphite paste, conducting polymer, ion-selective membrane). The ion-selective compounds have been incorporated in polyvinylchloride (PVC) membranes. Polypyrrole (PPy) acts as a solid contact and an intermediate layer between the ion-selective membrane and the graphite paste. As ion-complexing compounds tridodecylmethylammonium nitrate (TDMA-NO $\mathrm{NO}_{3}$ ) for nitrate, N,N,N',N'-tetra[cyclohexyl]diglycolic acid diamide and $\mathrm{N}, \mathrm{N}$-dicyclohexyl-N`,N`-dioctadecyl-diglycolic diamide for calcium(II) determinations have been used. The electrodes have been tested in drinking and well water samples by direct potentiometric determination and by titrations. The results have been compared to ion chromatography as the reference method. Both ion selective electrodes exhibit linear response from $10^{-5} \mathrm{~mol} / \mathrm{L}$ to $10^{-1} \mathrm{~mol} / \mathrm{L}$ respectively. The detection limits for the target ions are below $10^{-6} \mathrm{~mol} / \mathrm{L} \mathrm{based}$ on the respective ion.
\end{abstract}

Keywords: all-solid-state configuration, ion-selective electrode, drinking water, potentiometric titration, ion chromatography

\section{Introduction}

There is a great demand for mobile and in-field usable analyzers for ion analysis. Inexpensive, simple and fast chemical sensors should be used to check whether the level of an analyte is below or above the highest allowed concentration.

Laboratory based instrumental analysis methods like ion chromatography and atomic absorption spectrometry are not usable in field and require expensive equipment and qualified personnel. Electrochemical methods have the advantages of high sensitivity and selectivity, simplicity and low cost. Ion-selective electrodes in all-solid-state configuration without any liquid components can be used in an advantageous manner in field for potentiometric ion analysis due to their high sensitivity, simple construction form and good functionability. Conventional ion-selective electrodes consist of an internal reference electrode, which contains an inner liquid electrolyte and therefore are not suitable in field. In-field usable, easy-to-handle chemical analyzers are needed.

Since the discovery of graphite paste electrodes for electroanalytical applications by Adam, they have attracted much attention due to their advantages such as ease of preparation, stable response, and loss of internal electrolyte (Svancara, Kalcher, Walcarius, \& Vytras, 2012; Bobacka, Ivaska, \& Lewenstam, 2008; Radu et al., 2013). Development of all-solid-state ion-selective electrodes for determination of environmental important ions is of great interest in many application fields (Wang, Chou, \& Liu, 2003; Abramova, Moral-Vico, Soley, Ocana, \& Bratov, 2016; Enseleit et al., 2018; Yin, Li, \& Qin, 2017; Bomar, Owens, \& Murray, 2017; Wardek, 2014).

Instrumental laboratory analysis methods like ion chromatography and atomic absorption spectrometry require expensive and sophisticated equipment as well as laboratory-based infrastructure. Chemicals of high purity and qualified personnel are also needed. These analysis methods are not suitable for field analysis.

There is still a great need for ion determination of different ions in many different applications. Determination of calcium(II) as an important parameter for water hardness is needed in many different fields of water analysis. High nitrate contamination in ground, well and surface water has become a serious problem in Germany. The limiting value 
for nitrate in drinking water in the European Community is $50 \mathrm{mg} / \mathrm{L}$. Reduction of use of fertilizers is in discussion in order to reduce the nitrate entry in the environment. For both target ions user-friendly analyzers for field and continuous on-line determinations in real samples are needed in different application fields.

In this work we report on preparation, potentiometric characterization and analytical applications of new inexpensive, miniaturized, simple, robust and field-usable all-solid-state ion-selective electrodes based on graphite paste for nitrate and calcium(II) determinations in drinking water samples. The electrodes are characterized by thin functional polymeric layers and therefore allow an easy and reproducible electrode preparation.

\section{Experimental}

\subsection{Reagents and Materials}

All reagents were analytical grade and used without any further purification. All inorganic salts used were purchased from Sigma-Aldrich. All aqueous solutions were prepared with deionized water with a conductivity of $0.055 \mu \mathrm{S} / \mathrm{cm}$. As ion complexing compounds) N,N,N',N'-tetra[cyclohexyl]diglycolic acid diamide, $\mathrm{N}, \mathrm{N}$-dicyclohexyl-N', $\mathrm{N}^{\star}$-dioctadecyl-diglycolic diamide and $\mathrm{TDMA}^{-\mathrm{NO}_{3}}$ have been used. As plasticizers 2-nitrophenyloctyl ether and dibutyl phthalate have been used. Reagent grade, high molecular weight poly(vinyl chloride) (PVC), tetrahydrofuran, ethylene diaminetetraacetic acid disodium salt dihydrate, potassium tetrakis (4-chloro-phenyl)borate and pyrrole were purchased from Sigma Aldrich. Plasticizers, ion complexing compounds, of the highest purity were available and used without further purification. As eluents for ion chromatographic anion detection $\mathrm{Na}_{2} \mathrm{CO}_{3}(3.6 \mathrm{mmol} / \mathrm{L})$ and for cation detection $\mathrm{HNO}_{3}(1.7 \mathrm{mmol} / \mathrm{L})$ and dipicolinic acid $(0.7 \mathrm{mmol} / \mathrm{L})$ have been used.

\subsection{Apparatus and Reference Electrodes}

Potentiometric measurements were carried out at room temperature using pH/ion analyzer pMX 3000 and a laboratory measuring system LM 2000 with software LM remote from Xylem Analytics Germany Sales GmbH \& Co. KG Sensortechnik, Meinsberg. $\mathrm{Ag} / \mathrm{AgCl}$ reference electrodes (Kurt-Schwabe-Institut) with saturated $\mathrm{KCl}$ electrolyte have been used. An ion chromatography system (IC 850 Metrohm, Switzerland) has been used for the reference analysis.

\section{Results and Discussion}

\subsection{Electrode Preparation}

The ion-selective all-solid-state electrodes consist of following different functional layers:

- First layer: graphite paste (mixture of graphite powder and resin).

- Second layer: polypyrrole (PPy) as conducting polymer.

- Third layer: ion-selective (polyvinyl) chloride membrane.

All layers are incorporated in an electrode plastic body and adhere well on the corresponding substrate. PPy is depleted onto graphite paste surface by electropolymerization of pyrrole. The PVC based membranes were prepared by dissolving of the ion-complexing compound together with the plasticizer, the PVC and the additive in tetrahydrofuran. PPy acts as a solid contact and intermediate layer between the ion-selective membrane und the graphite paste. It replaces the internal liquid electrolyte of conventional ion-selective electrodes. The ion-selective cocktail with the immobilized ion-complexing compound is then drop-casted onto the PPy-layer. Electrode preparation and optimized membrane composition are described elsewhere (Schwarz, Trommer, \& Mertig, 2016; Schwarz, Trommer, \& Mertig, 2018; Schwarz, Trommer, Gerlach, \& Mertig, 2018).

Figure 1 shows a photograph (a) and a schematic view with the functional layers (b) of a miniaturized ion-selective electrode in all-solid-state configuration. 


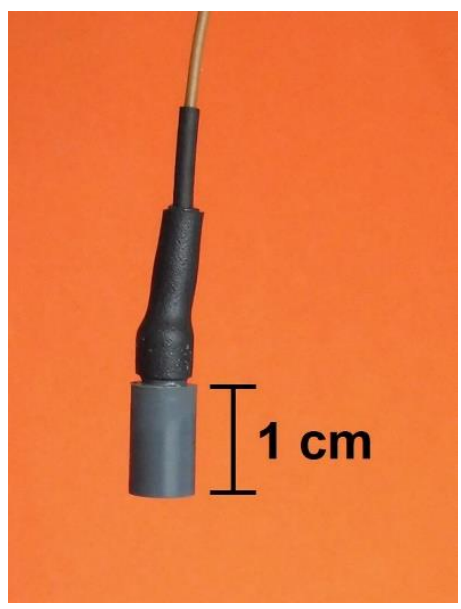

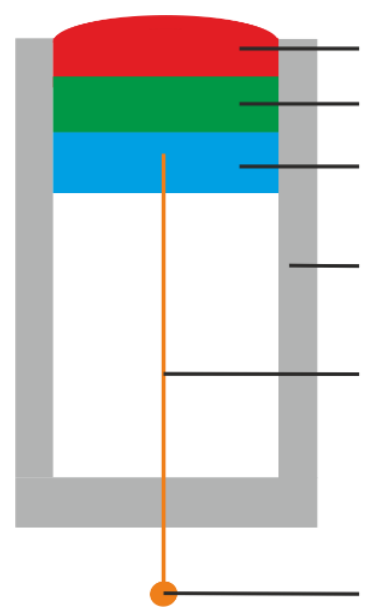

ion-selective PVC-membrane polypyrrole

graphite paste

plastic sensor body

conducting drain

electrical contact

Figure 1. Photography (a) and schematic view (b) of an ion-selective, all-solid-state electrode

Commercially available ion-complexing reagents for target ions are used and shown in Table 1. For preparation of calcium(II)-selective electrodes both diamides have been used and show comparable response behavior.

Table 1. Membrane compositions

\begin{tabular}{lcc}
\hline $\begin{array}{l}\text { membrane } \\
\text { component }\end{array}$ & Calcium(II)-selective electrode & Nitrate-selective electrode \\
\hline ionophore & $\begin{array}{l}\boldsymbol{a}) N, N, N^{\prime}, N^{\prime} \text {-tetra[cyclohexyl]diglycolic acid diamide } \\
\text { b) } N, N \text {-dicyclohexyl- } N^{\prime}, N^{\prime} \text {-dioctadecyl-diglycolic diamide }\end{array}$ & tridodecylmethylammonium nitrate \\
\hline plasticizer & 2-nitrophenyl octyl ether & dibutyl phthalate \\
\hline polymer & poly(vinyl chloride) & poly(vinyl chloride) \\
\hline additive & potassium tetrakis(4chlorophenyl)-borate & --- \\
\hline
\end{tabular}

\subsection{Calcium(II)-Selective All-Solid-State Electrodes}

The response behavior of calcium(II)-selective electrodes in standard and real samples including the corresponding calibration curve are shown in Figure 2. The electrodes were conditioned before measurements for $12 \mathrm{~h}$ in $10^{-3} \mathrm{~mol} / \mathrm{L}$ $\mathrm{CaCl}_{2}$ solution.

The relative standard deviation (RSD) for calcium(II) determinations in the concentration range of $10^{-3} \mathrm{~mol} / \mathrm{L}$ till $10^{-5}$ $\mathrm{mol} / \mathrm{L}$ was below $5 \%(\mathrm{n}=9)$.

As real samples different drinking water samples have been investigated. After calibration in standard solutions, the electrodes were washed with deionized water, and then immersed in the target sample. The electrodes show stable potentials in standard and real samples. Following calcium(II) contents for different drinking water samples were evaluated by direct potentiometry with the new ion-selective electrodes:

- $\quad$ sample 1 (drinking water from Freiberg, Germany): $23 \mathrm{mg} / \mathrm{L}$,

- $\quad$ sample 2 (drinking water from Lützschnitz, Germany): $129 \mathrm{mg} / \mathrm{L}$.

Figure 3 shows the ion chromatogram of sample 1. Reference analysis by ion chromatography yielded a calcium(II) amount of $29 \mathrm{mg} / \mathrm{L}$.

Figure 4 shows a potentiometric titration curve (a) and the first derivative (b) of a drinking water sample (Karsdorf, Germany) with the new calcium(II)-selective electrode. The drinking water samples have been adjusted to $\mathrm{pH} 12 \mathrm{by}$ adding $\mathrm{NaOH}(2 \mathrm{~mol} / \mathrm{L})$. The calcium(II) amount obtained by titration using new calcium(II)-selective electrode yielded $35 \mathrm{mg} / \mathrm{L}$. The titration curve shows a sharp and significant potential jump which could be used successfully for analytical applications.

In figure 5 a chromatogram of a drinking water sample (Karsdorf, Germany) is illustrated. The obtained calcium(II) 
value by ion chromatography was $38 \mathrm{mg} / \mathrm{L}$. The reference analysis was carried out by titration using calcon carbon acid as color indicator revealed a calcium(II) amount of $35 \mathrm{mg} / \mathrm{L}$. Thus, the results obtained by different analysis methods show good accordance.

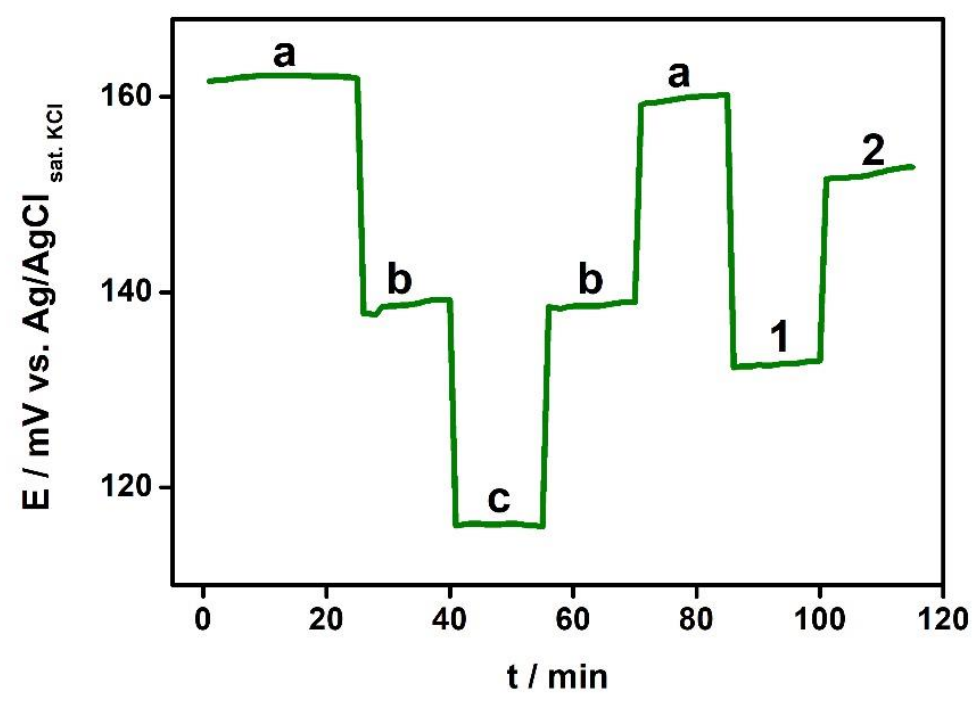

a

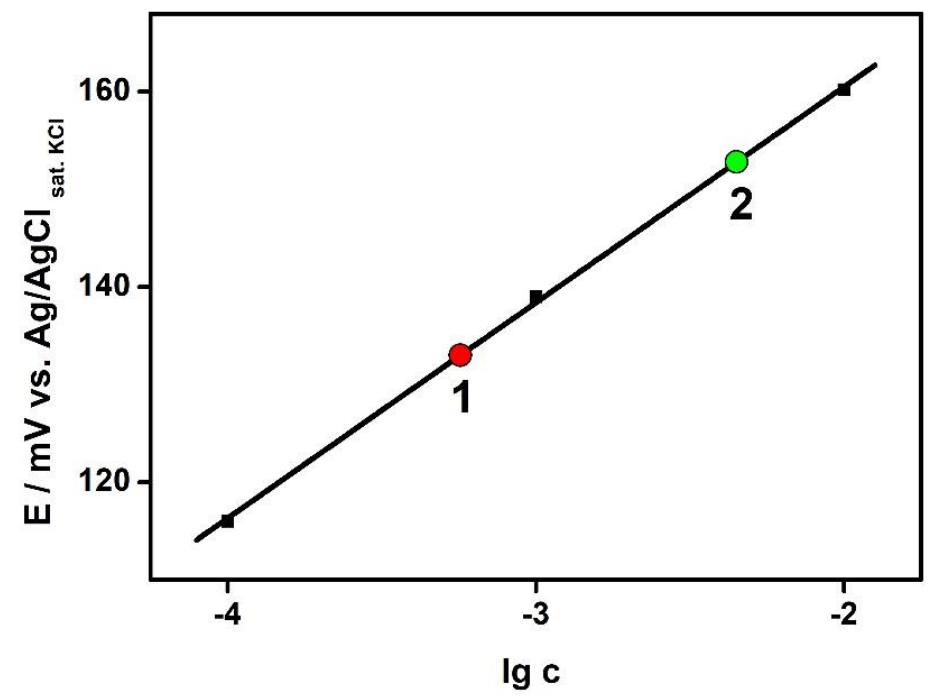

b

Figure 2. Response behavior (a) and corresponding calibration curve (b) of a calcium(II)-selective electrode in standard and real samples; $\mathrm{CaSO}_{4}$ standards: a: $10^{-2} \mathrm{~mol} / \mathrm{L}, \mathrm{b}: 10^{-3} \mathrm{~mol} / \mathrm{L}$, c: $10^{-4} \mathrm{~mol} / \mathrm{L}$; sample 1: drinking water (Freiberg, Germany), sample 2: drinking water (Lützschnitz, Germany) 


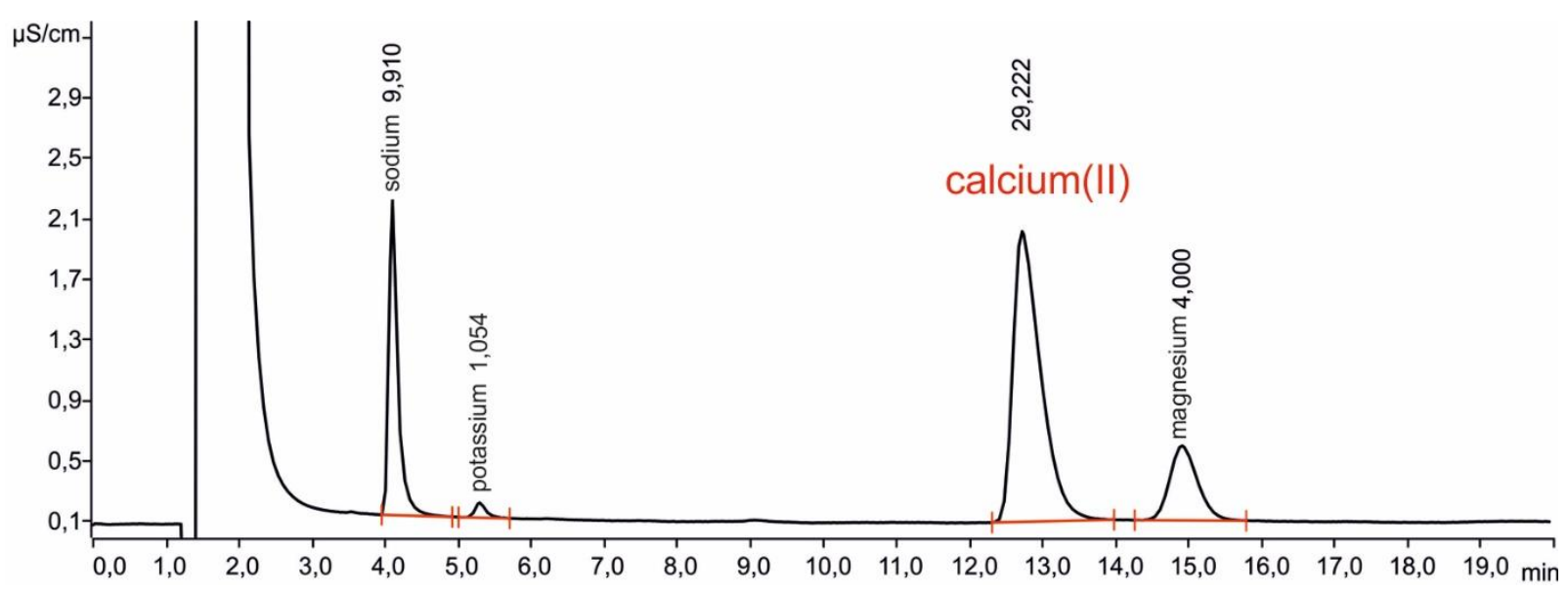

Figure 3. Chromatogram of a drinking water sample (Freiberg, Germany)

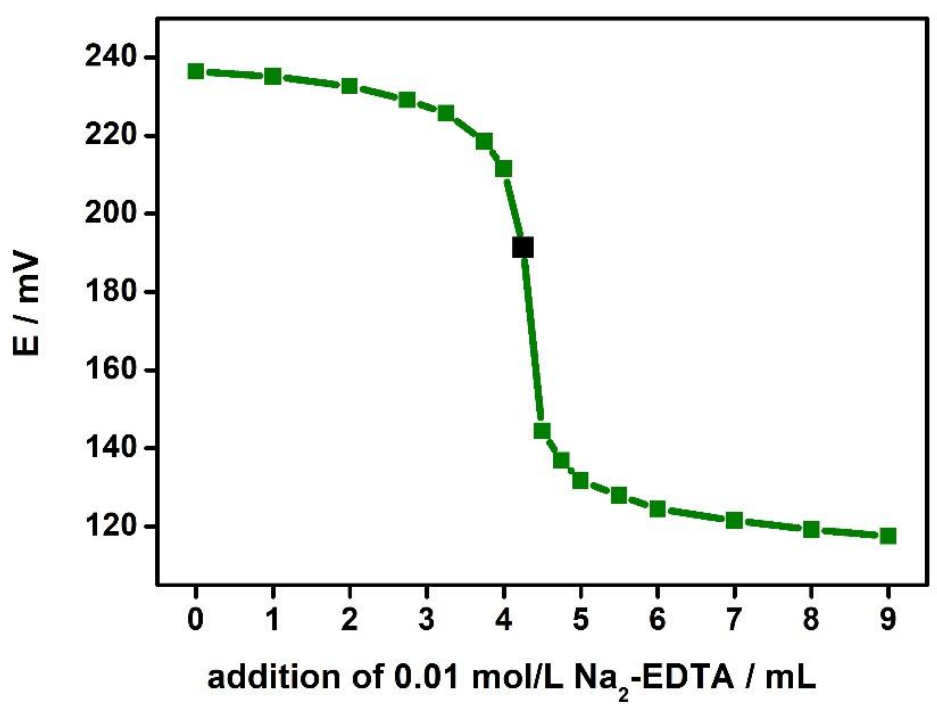

$\mathbf{a}$

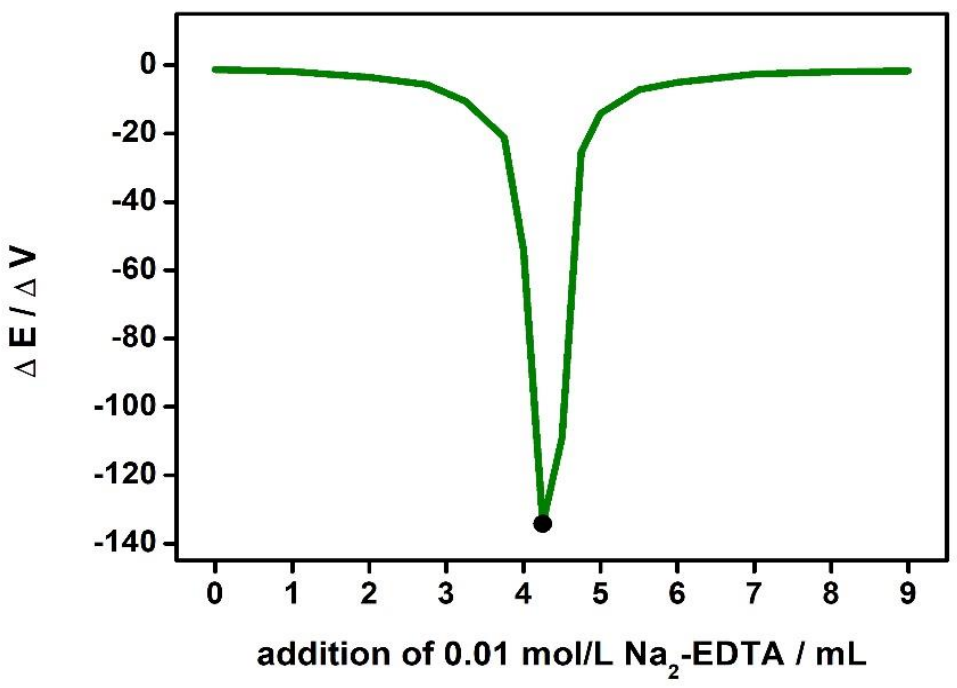

b

Figure 4. Titration curve (a) and first derivative (b) of a drinking water sample (Karsdorf, Germany) 


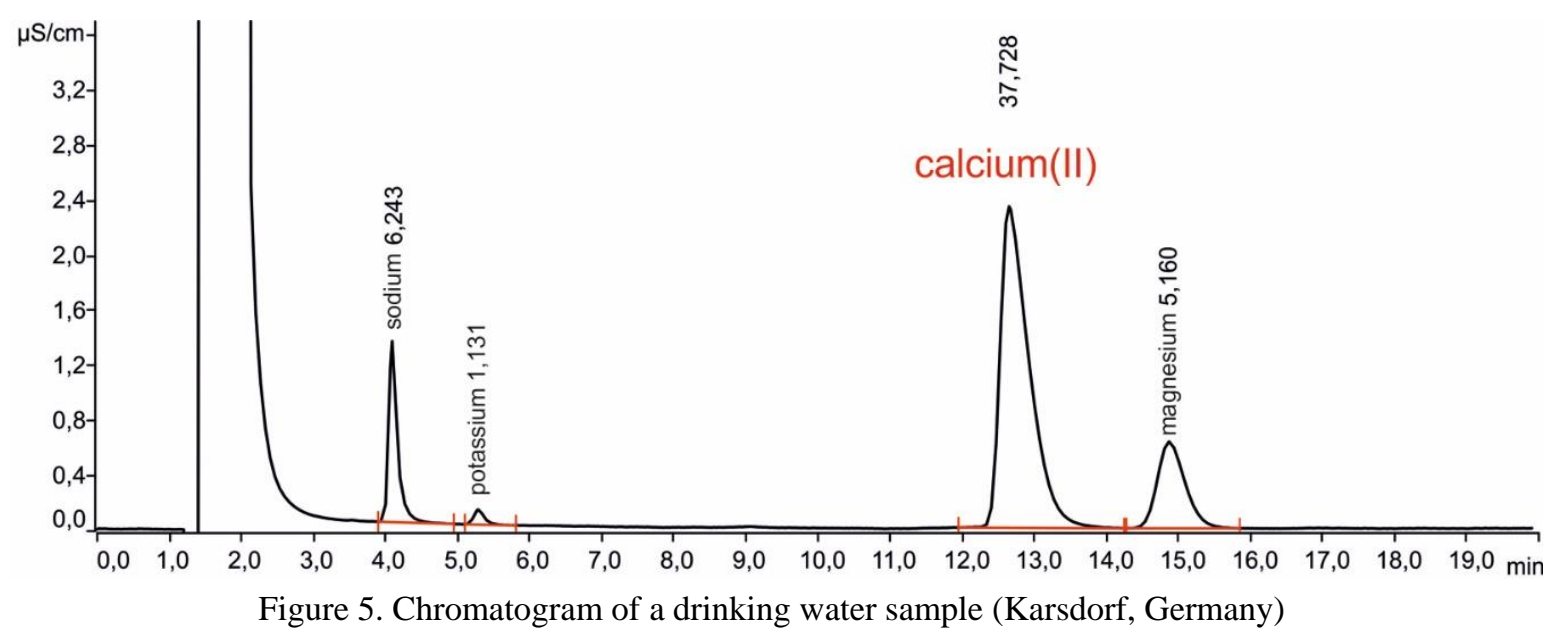

The calcium(II)-selective electrodes show sensitivities in the linear range $\left(10^{-5} \mathrm{~mol} / \mathrm{L}-10^{-1} \mathrm{~mol} / \mathrm{L}\right)$ of $>25 \mathrm{mV} / \mathrm{decade}$ in average. The results obtained by potentiometry with new calcium(II)-selective electrodes show good accordance to results of ion chromatography.

\subsection{Nitrate-Selective All-Solid-State Electrodes}

Figure 6 shows the response behavior of a nitrate-selective electrode in standard and different drinking water samples, as well as the corresponding calibration curve. Following nitrate concentrations in the samples have been determined by direct potentiometry using the new nitrate electrodes. In brackets, values obtained by ion chromatography are shown. The results of the different analysis methods agree well.

- $\quad$ sample 1 (drinking water from Freiberg, Germany): $14 \mathrm{mg} / \mathrm{L}(15 \mathrm{mg} / \mathrm{L})$,

- $\quad$ sample 2 (drinking water from Döbeln, Germany): $25 \mathrm{mg} / \mathrm{L}(23 \mathrm{mg} / \mathrm{L})$,

- $\quad$ sample 3 (drinking water from Chemnitz, Germany): $\quad 9 \mathrm{mg} / \mathrm{L}(10 \mathrm{mg} / \mathrm{L})$.

In Figure 7 a chromatogram of a drinking water sample is shown. The comparison of results well justifies the potential of these electrodes for direct potentiometric nitrate determination in drinking water samples without any addition of chemicals and sample preparation.

In the concentration range $10^{-5} \mathrm{~mol} / \mathrm{L}$ till $10^{-1} \mathrm{~mol} / \mathrm{L}$ the nitrate-selective electrode exhibited linear Nernstian potential response. The average sensitivity is $>-55 \mathrm{mV} /$ decade. A selectivity coefficient of -1.6 for chloride as the main interfering ion was evaluated after the fixed interference method. The relative standard deviation (RSD) for nitrate determination in the concentration range of $10^{-3} \mathrm{~mol} / \mathrm{L}$ till $10^{-1} \mathrm{~mol} / \mathrm{L}$ was below $4 \%(\mathrm{n}=5)$. The electrodes can be used in the pH-range of 3-9. 


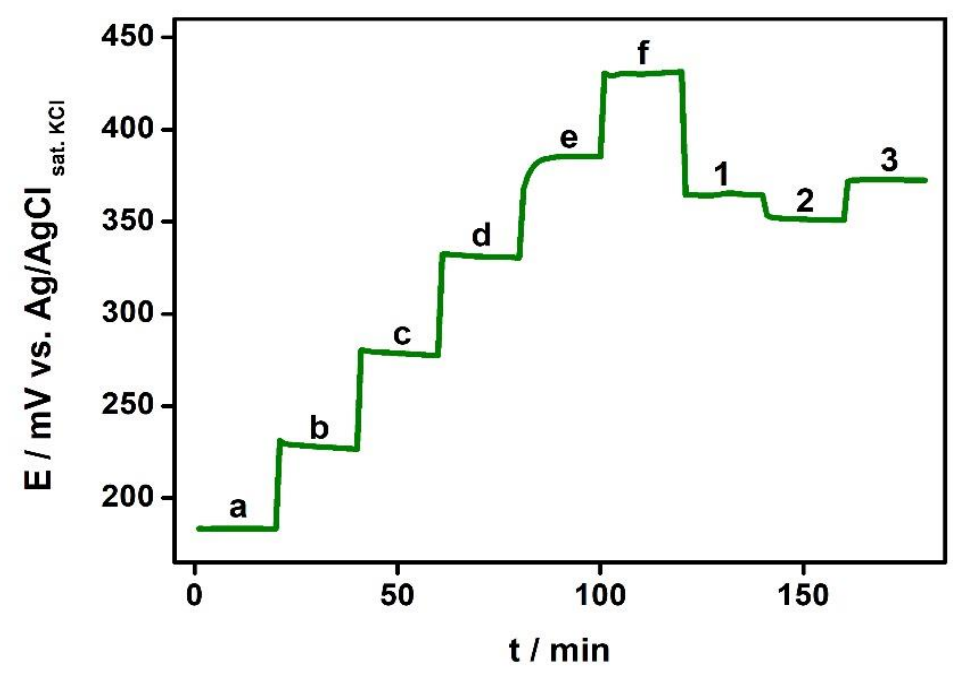

a

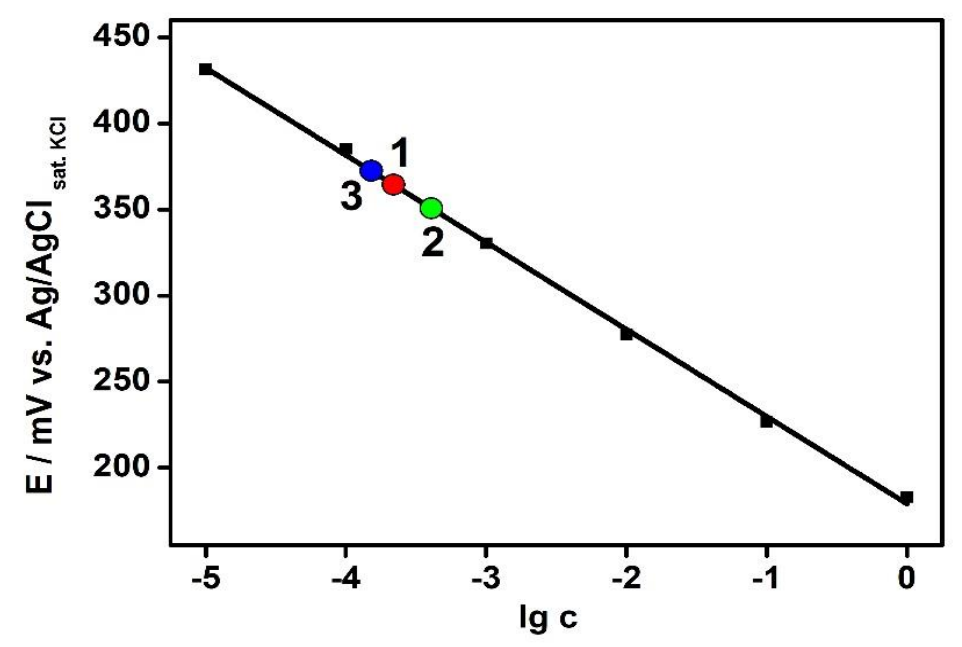

b

Figure 6. Response behavior (a) and calibration curve (b) of a nitrate-selective electrode in standard and real samples; $\mathrm{NH}_{4} \mathrm{NO}_{3}$ standards a $1 \mathrm{~mol} / \mathrm{L}$, b $10^{-1} \mathrm{~mol} / \mathrm{L}$, c $10^{-2} \mathrm{~mol} / \mathrm{L}, \mathrm{d} 10^{-3} \mathrm{~mol} / \mathrm{L}$, e $10^{-4} \mathrm{~mol} / \mathrm{L}$, f $10^{-5} \mathrm{~mol} / \mathrm{L}$; drinking water samples: 1 Freiberg, 2 Döbeln, 3 Chemnitz

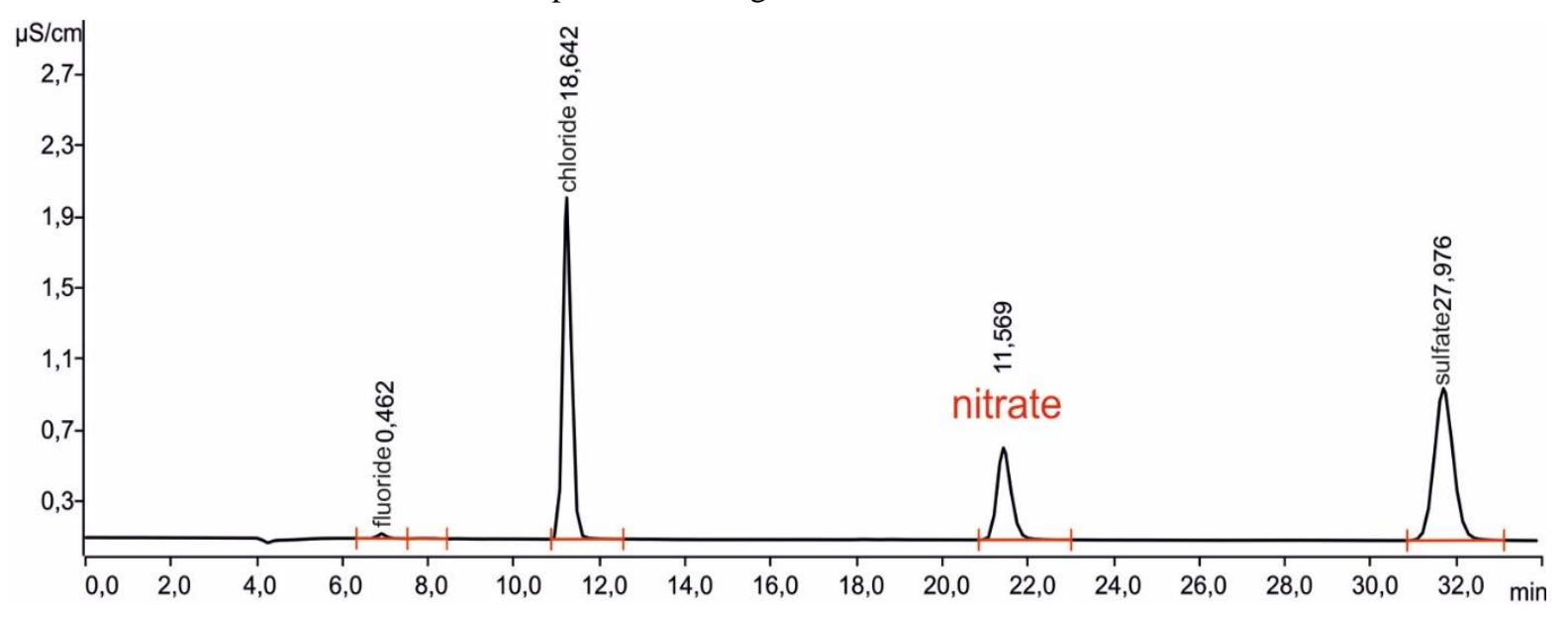

Figure 7. Chromatogram of a drinking water sample (Freiberg, Germany) 


\section{Conclusions}

The new solid-contact, ion-selective electrodes based on graphite paste show remarkable stable and reproducible potentials. They are characterized by simple construction and all-solid-state configuration. Both electrodes provide a Nernstian response for both target ions in the linear range. The conducting polymer polypyrrole acts as a solid contact, replacing the inner electrolyte solution. Results obtained by potentiometric ion determinations using the new ion-selective electrodes are comparable with results obtained from ion chromatography. In most cases a good consistency between these different analytical methods is achieved. Both electrodes can be used successfully in drinking water analysis using direct potentiometry. The calcium(II)-selective electrodes also show good results in potentiometric titrations of tap water samples. The new developed all-solid-state ion-selective electrodes are particularly attractive for mobile and decentralized ion analysis due to their low cost, simple instrumentation, loss of liquid electrolyte and high durability. Furthermore, they are miniaturizable and easy-to-handle. Experiments concerning long-term behavior under real environmental conditions in field and under the influence of different interfering ions will be carried out in future.

\section{Acknowledgement}

The authors thank Andreas Klockow, Marcel Rudelt and Felix Trommer for help in sensor construction and preparation.

\section{References}

Abramova, N., Moral-Vico, J., Soley, J., Ocana, C., \& Bratov, A. (2016). Solid contact ion sensor with conducting polymer layer copolymerized with the ion-selective membrane for determination of calcium in blood serum. Analytica Chimica Acta, 943, 50-57. https://doi.org/10.1016/j.aca.2016.09.017

Bobacka, J., Ivaska, A., \& Andrzej, L. A. (2008). Potentiometric ion sensors. Chem. Rev., 108, 329-351. https://doi.org/10.1021/cr068100w

Bomar, E. M., Owens, G. S., \& Murray, G. M. (2017). Nitrate ion selective electrode based ion imprinted poly(N-methylpyrrole). Chemosensors, 5(1), 2. https://doi.org/10.3390/chemosensors5010002

Enseleit, U., Berthold, M., Feller, C., Partsch, U., Körner, S., \& Vonau, W. (2018). Chalcogenide glass based heavy metal sensors. Sensors \& Transducers, 219(1), 1-8.

Radu, A., Radu, T., McGraw, C., Dillingam, P., Anastasova-Ivanova, S., \& Diamond, D. (2013). Ion selective electrodes in environmental analysis. Journal of the Serbian Chemical Society, 78(11), 1729-1761. https://doi.org/10.2298/JSC130829098R

Schwarz, J., Trommer, K., \& Mertig, M. (2016). Novel Screen-printed all-solid-state copper (II)-selective electrode for mobile environmental analysis. American Journal of Analytical Chemistry, 7, 525-532. https://doi.org/10.4236/ajac.2016.77048

Schwarz, J., Trommer, K., \& Mertig, M. (2018). Solid-contact ion-selective electrodes based on graphite paste for potentiometric nitrate and ammonium determinations. American Journal of Analytical Chemistry, 9, 591-601. https://doi.org/10.4236/ajac.2018.912043

Schwarz, J., Trommer, K., Gerlach, F., \& Mertig, M. (2018). All-solid-state screen-printed sensors for potentiometric calcium (II) determinations in environmental samples. American Journal of Analytical Chemistry, 9, 113-123. https://doi.org/10.4236/ajac.2018.93010

Svancara, I., Kalcher, K., Walcarius, A., \& Vytras, K. (Eds.) (2012). Electroanalysis with Carbon Paste electrodes. CRC Press. https://doi.org/10.1201/b11478

Wang, S. H., Chou, T. C., \& Liu, C. C. (2003). Development of a solid-state thick film calcium ion-selective electrode. Sensors and Actuators B, 96, 709-716. https://doi.org/10.1016/S0925-4005(03)00571-9

Wardek, C. (2014). Solid contact nitrate ion selective electrode based on ionic liquid with stable and reproducible potential. Electroanalysis, 26, 864-872. https://doi.org/10.1002/elan.201300590

Yin, T., Li, J., \& Qin, W. (2017). An All-solid-state polymeric membrane $\mathrm{Ca}^{2+}$-selective electrode based on Hydrophobic alkyl-chain-functionalized graphene oxide. Electroanalysis, 29(3), 821-827.

https://doi.org/10.1002/elan.201600383

\section{Copyrights}

Copyright for this article is retained by the author(s), with first publication rights granted to the journal.

This is an open-access article distributed under the terms and conditions of the Creative Commons Attribution license (http://creativecommons.org/licenses/by/4.0/). 